\title{
Salivary Gland Mucoepidermoid Carcinoma
}

National Cancer Institute

\section{Source}

National Cancer Institute. Salivary Gland Mucoepidermoid Carcinoma. NCI Thesaurus. Code C5908.

A carcinoma that arises from the salivary glands. It is the most common primary carcinoma of the salivary glands and usually presents as a firm and painless mass. It is characterized by the presence of epidermoid cells, mucus producing cells, and cells of intermediate type. The majority of cases have a favorable outcome. 